\title{
Rapid pseudo five-component synthesis of intensively blue luminescent 2,5-di(hetero)arylfurans via a Sonogashira-Glaser cyclization sequence
}

Fabian Klukas, Alexander Grunwald, Franziska Menschel and Thomas J. J. Müller*

Open Access

\author{
Full Research Paper \\ Address: \\ Heinrich-Heine Universität Düsseldorf, Institut für Organische Chemie \\ und Makromolekulare Chemie, Universitätsstraße 1, D-40225 \\ Düsseldorf, Germany \\ Email: \\ Thomas J. J. Müller - ThomasJJ.Mueller@uni-duesseldorf.de \\ * Corresponding author \\ Keywords: \\ C-C coupling; copper; DFT; fluorescence; furans; mircowave-assisted \\ synthesis; multicomponent reactions; palladium
}

Beilstein J. Org. Chem. 2014, 10, 672-679.

doi:10.3762/bjoc. 10.60

Received: 13 December 2013

Accepted: 12 February 2014

Published: 18 March 2014

This article is part of the Thematic Series "Multicomponent reactions II" and is dedicated to Prof. Dr. Rainer Weinkauf on the occasion of his 60th birthday.

Associate Editor: J. P. Wolfe

(c) 2014 Klukas et al; licensee Beilstein-Institut. License and terms: see end of document.

\begin{abstract} DFT computations.

\section{Introduction}

Multicomponent reactions (MCRs) [1-5] are conceptually diversity-oriented syntheses (DOS) [6,7] and have been developed to powerful tools for exploring broad ranges of different structural and functional characteristics. In addition, MCRs address the very fundamental principles of reaction efficiency and atom economy. Besides lead finding in pharmaceutical and medicinal chemistry [8-10] MCRs have also been recognized as a DOS tool for approaching functional $\pi$-systems [11] such as luminescent chromophores [6].
\end{abstract}

2,5-Di(hetero)arylfurans are readily accessible in a pseudo five-component reaction via a Sonogashira-Glaser coupling sequence followed by a superbase-mediated (KOH/DMSO) cyclization in a consecutive one-pot fashion. Besides the straightforward synthesis of natural products and biologically active molecules all representatives are particularly interesting due to their bright blue luminescence with remarkably high quantum yields. The electronic structure of the title compounds is additionally studied with
Interestingly, multicomponent syntheses of symmetrically substituted furans have remained rare [12,13], although furans are ubiquitous in nature [14]. In particular, 2,5-di(hetero)arylfurans are structural units with pronounced biological activities [15] and besides in natural products $[16,17]$ they are also present in potential pharmaceuticals for the treatment of human African trypanosomiasis [18-20], and against human renal cancer cells [21-23]. Furthermore, 2,5-di(hetero)arylfurans have been reported as photonic chromophores [24]. However, the 
electronic and photophysical properties of 2,5-di(hetero)aryl furans have only been occasionally studied [25-27].

The classical synthesis of symmetrical 2,5-disubstituted furans proceeds via Paal-Knorr synthesis [28]. Due to sophisticated starting materials this very general pathway is often not suitable for a DOS approach. In addition, some starting materials are either not readily available or quite expensive. 2,5-dihalogenated furans can be in principle employed in cross-coupling reactions, however, the poor stability of these dihalogenated precursors renders this approach very tedious [29]. Recent publications report gold-catalyzed syntheses of di(hetero)arylfurans starting from arylbutadiynes [30,31]. However, the major drawback of this approach is the complex, time-consuming preparation of the complicated gold catalyst and the separate synthesis of the butadiyne substrates. In a similar study arylbutadiynes prepared by Glaser homocoupling were converted into symmetrical 2,5-di(hetero)arylfurans [32] employing the superbase system $\mathrm{DMSO} / \mathrm{KOH} / \mathrm{H}_{2} \mathrm{O}$ in the terminal cyclization step [33]. The same approach was applied to butadiynes that were formed by oxidative dimerization of arylalkynes with a $\mathrm{Cu} / \mathrm{Fe}$ catalyst [34]. Apart from using reactive terminal alkynes as starting materials the major drawbacks of this approach are clearly the extended reaction times (3-6 d) and the removal of the catalyst after the coupling step.

Recently, we became particularly interested in sequentially Pd-catalyzed processes [35] starting from (hetero)aryl iodides [36]. In particular, the $\mathrm{Pd}-\mathrm{Cu}$-catalyzed Sonogashira-Glaser sequence represents a highly intriguing combination of a crosscoupling and an oxidation reaction in a one-pot fashion [37]. By this approach we can efficiently avoid the major disadvantage of starting from terminal alkynes, which are occasionally unstable and tend to undergo polymerization. Based upon the Sonogashira-Glaser sequence we recently presented a straightforward one-pot sequence for the synthesis of 2,5di(hetero)arylthiophenes [38]. Here, we report the methodological development of a novel multicomponent synthesis of symmetrical 2,5-(hetero)arylfurans in the sense of a consecutive one-pot sequence. In addition, the photophysical and electronical properties are studied and the electronic structure is investigated by DFT calculations.

\section{Results and Discussion Synthesis}

Prior to setting up the one-pot sequence we first optimized the conditions of the terminal cyclization step for the formation of 2,5-diphenylfuran (2a, Table 1) starting from 1,4-diphenylbutadiyne (1a) as a substrate. Just upon eyesight a remarkable luminescence of 2a caught our attention and we were encouraged to perform photophysical studies with these products as well (vide infra). In a set of experiments the reaction times under microwave heating (the temperature optimum of $130^{\circ} \mathrm{C}$ was quickly identified by screening experiments), the water/ $\mathrm{KOH}$ ratio, and the concentrations were varied.

\begin{tabular}{|c|c|c|c|c|c|}
\hline \multicolumn{2}{|c|}{$\mathrm{Ph}=\overline{\overline{1 a}} \mathrm{Pr}$} & \multicolumn{2}{|c|}{$\frac{\mathrm{H}_{2} \mathrm{O}, \mathrm{KOH}}{\mathrm{DMSO}, 130^{\circ} \mathrm{C} \mathrm{mw}}$} & \multicolumn{2}{|c|}{$\underbrace{\mathrm{Ph}}_{\mathbf{2 a}}$} \\
\hline Entry & $\begin{array}{c}\mathrm{H}_{2} \mathrm{O} \\
\text { [equiv] }\end{array}$ & $\begin{array}{l}\mathrm{KOH} \\
\text { [equiv] }\end{array}$ & $\begin{array}{c}\text { DMSO } \\
{[\mathrm{mL} / \mathrm{mmol}]}\end{array}$ & $\begin{array}{l}\text { Time } \\
{[\mathrm{h}]}\end{array}$ & $\begin{array}{c}\text { Yield }^{a} \\
{[\%]}\end{array}$ \\
\hline 1 & 2 & 2 & 4 & 1 & 53 \\
\hline 2 & 2 & 2 & 4 & 3 & 24 \\
\hline 3 & 10 & 2 & 4 & 1 & 25 \\
\hline $4^{b}$ & 2 & 2 & 4 & 1 & 34 \\
\hline $5^{c}$ & 2 & 2 & 4 & 1 & 36 \\
\hline $6^{c}$ & 16 & 10 & 4 & 1 & 50 \\
\hline $7^{d}$ & 8 & 10 & 4 & 1 & 40 \\
\hline $8^{\mathrm{d}, \mathrm{e}}$ & 8 & 10 & 4 & 6 & 43 \\
\hline 9 & 2 & 2 & 8 & 1 & 58 \\
\hline 10 & 4 & 4 & 8 & 1 & 64 \\
\hline 11 & 2 & 8 & 16 & 1 & 13 \\
\hline 12 & 8 & 8 & 16 & 1 & 84 \\
\hline 13 & 12 & 12 & 16 & 1 & 79 \\
\hline
\end{tabular}

a Isolated yield after chromatography on silica gel. ${ }^{\mathrm{b}} \mathrm{In}$ the presence of $2 \mathrm{~mol} \% \mathrm{PdCl}_{2}\left(\mathrm{PPh}_{3}\right)_{2}$. ${ }^{\text {In }}$ the presence of $5 \mathrm{~mol} \% \mathrm{Cul}, 15 \mathrm{~mol} \%$ DMEDA. ${ }^{\mathrm{d}} \mathrm{n}$ the presence of $5 \mathrm{~mol} \% \mathrm{Cul}, 15 \mathrm{~mol} \%$ 1,10-phenanthroline. ${ }^{\mathrm{e}}$ Conductive heating (oilbath at $130^{\circ} \mathrm{C}$ ).

In the course of our studies a related work using copper catalysts with the electronrich DMEDA ( $N, N$ '-dimethylethylenediamine) or the electronpoor 1,10-phenanthroline as ligands was published [32], however, in our hands no favorable effect on the isolated yields of 2a was found (Table 1, entries 4-8). The cyclization works equally well with conductive heating in an oil bath instead of microwave heating (Table 1, entry 8). At higher concentrations we always observed the formation of byproducts that were not detectable by GC, although 1a was completely consumed. An isolated black solid with an elemental analysis matching with the elemental composition of 2a was partially soluble in acetone and THF. The supernatant of the THF extraction was analyzed by MALDI-TOF mass spectrometry indicating the formation of oligomers with $\mathrm{m} / \mathrm{z}=422$ to 1046 . We could efficiently suppress this oligo- and polymerization by increasing the amount of solvent, i.e. by dilution (Table 1, entries 9-13). Additionally increasing the concentration of $\mathrm{KOH}$ and water also proved to be beneficial (Table 1, entries 10-13). The optimal conditions for this cyclization are marked in entry 12 of Table 1. 
With these optimized conditions in hand we started to concatenate the one-pot sequence by generating the required 1,4butadiynes from (hetero)aryl iodides. First, the Sonogashira-Glaser sequence had to be performed in DMSO as a solvent and in the presence of atmospheric oxygen for the Glaser step. Starting from iodobenzene (3a) and trimethylsilylacetylene (TMSA) the cross-coupling in DMSO proceeded uneventfully and the yield of the Glaser product 1a was found to be $80 \%$, i.e. approximately the same yield as for the sequence in THF as a solvent (Scheme 1) [37]. Most favorably no additional cosolvent was needed for increasing the solubility of the fluoride source [38]. For an optimal Glaser step vigorous stirring is required to ensure an efficient air saturation of the solvent.

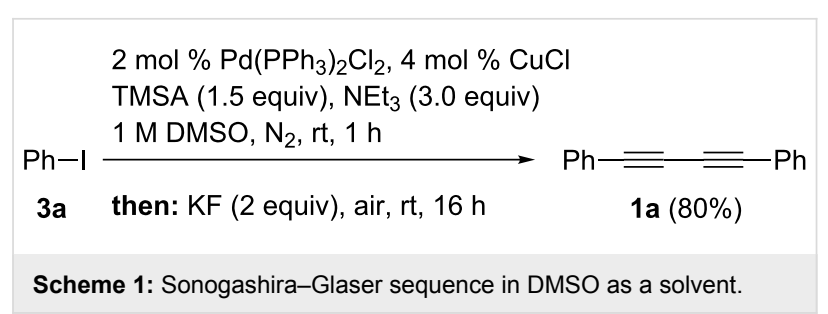

Finally, starting from (hetero)aryl iodides 3 and TMSA we combined the Sonogashira-Glaser sequence with the cyclization step into a one-pot sequence and studied the substrate scope of this pseudo five-component synthesis of 2,5-di(hetero)arylfurans 2 (Scheme 2). All reactions were performed on a $2 \mathrm{mmol}$ scale.

\section{$2 \mathrm{~mol} \% \mathrm{Pd}\left(\mathrm{PPh}_{3}\right)_{2} \mathrm{Cl}_{2}, 4 \mathrm{~mol} \% \mathrm{CuCl}$ \\ TMSA (1.5 equiv), $\mathrm{NEt}_{3}$ (3.0 equiv) \\ DMSO, under $\mathrm{N}_{2}, \mathrm{rt}, 1 \mathrm{~h}$}

(hetero)aryl-I

3

then: $\mathrm{KF}$, air, $\mathrm{rt}, 24 \mathrm{~h}$

then: DMSO, $\mathrm{KOH}$ (8 equiv), $\mathrm{H}_{2} \mathrm{O}$ (8 equiv) $\mathrm{mw}\left(130^{\circ} \mathrm{C}\right), 1 \mathrm{~h}$

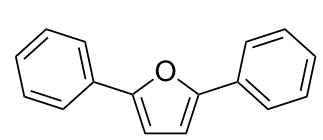

2a (44\%)<smiles>Cc1ccccc1-c1ccc(-c2ccccc2C)o1</smiles>

2b (51\%)

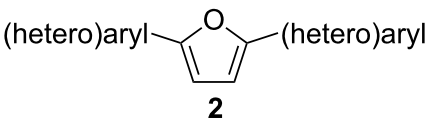

15 examples (19-65\%)<smiles>Cc1ccc(-c2ccc(-c3ccc(C)cc3)o2)cc1</smiles>

2d $(40 \%)$<smiles>Cc1cc(C)cc(-c2ccc(-c3cc(C)cc(C)c3)o2)c1</smiles>

2 e $(22 \%)$<smiles>Cc1cccc(-c2ccc(-c3cccc(C)c3)o2)c1</smiles>

2c $(65 \%)$<smiles>COc1cccc(-c2ccc(-c3cccc(OC)c3)o2)c1</smiles>

$2 f(39 \%)$<smiles>COc1cc(-c2ccc(-c3cc(OC)c(OC)c(OC)c3)o2)cc(OC)c1OC</smiles>

2g $(27 \%)$<smiles>COc1ccc(C)cc1-c1ccc(-c2cc(C)ccc2OC)o1</smiles>

2h (42\%)<smiles>c1ccc2c(-c3ccc(-c4cccc5ccccc45)o3)cccc2c1</smiles>

$2 \mathbf{i}(60 \%)$<smiles>c1ccc2cc(-c3ccc(-c4ccc5ccccc5c4)o3)ccc2c1</smiles>

$\mathrm{HO}$<smiles>CCc1cccc(-c2ccc(-c3cccc(CO)c3)o2)c1</smiles>

2k $(43 \%)^{\mathrm{a}}$<smiles>c1csc(-c2ccc(-c3cccs3)o2)c1</smiles>

2l (31\%)

2j $(21 \%)$<smiles>c1cc(-c2ccc(-c3ccsc3)o2)cs1</smiles>

$2 \mathrm{~m}(20 \%)$<smiles>Fc1ccc2cc(-c3ccc(-c4cc5ccccc5c5ccccc45)o3)c3ccccc3c2c1</smiles>

2n $(51 \%)$<smiles>Fc1ccc(-c2ccc(-c3ccc(F)cc3)o2)cc1</smiles>

$20(25 \%)$

Scheme 2: Pseudo five-component Sonogashira-Glaser cyclisation synthesis of 2,5-di(hetero)arylfurans 2 ( ${ }^{\mathrm{a}}$ obtained from the THP-protected precursor). 
The structural assignments of all furans 2 were unambiguously supported by ${ }^{1} \mathrm{H}$ and ${ }^{13} \mathrm{C}$ NMR spectroscopy, mass spectrometry, and combustion analysis (HRMS in case of $\mathbf{2} \mathbf{j}$ and $\mathbf{2} \mathbf{m}$ ). Due to the poor solubility of some compounds all spectra were recorded in DMSO at room temperature, whereas the compounds $2 \mathbf{r}$ and $2 \mathbf{p}$ were measured at $80{ }^{\circ} \mathrm{C}$.

The yields of the obtained 2,5-di(hetero)arylfurans 2 are moderate to good and the employed (hetero)aryl substituents can be electroneutral (2a, $\mathbf{2 i}, \mathbf{2} \mathbf{j})$ and electronrich $(\mathbf{2} \mathbf{b}-\mathbf{2 h}, \mathbf{2} \mathbf{k}$,

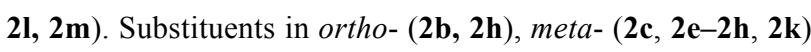
and para-position (2d, 2g, 2o) are well tolerated. Polar substituents like alcohols (2k) can also be employed in the sequence. From the literature it is known that the naturally occurring compound $\mathbf{2 h}[16,17]$ and 2,5-bis(3,4,5trimethoxyphenyl)furan (2g) are highly biological active [39]. Compound $\mathbf{2 k}$ is structurally related to small molecule inhibitors of p53-HDM-2 [21-23].

\section{Electronic properties and computational studies}

All title compounds 2 display strong fluorescence in solution and in the solid state upon UV excitation (Figure 1). Therefore, the absorption and emission spectra of all compounds 2 were recorded in dichloromethane and the fluorescence quantum yields $\Phi_{\mathrm{f}}$ were determined with coumarin 1 or $p$-terphenyl as references (Table 2).

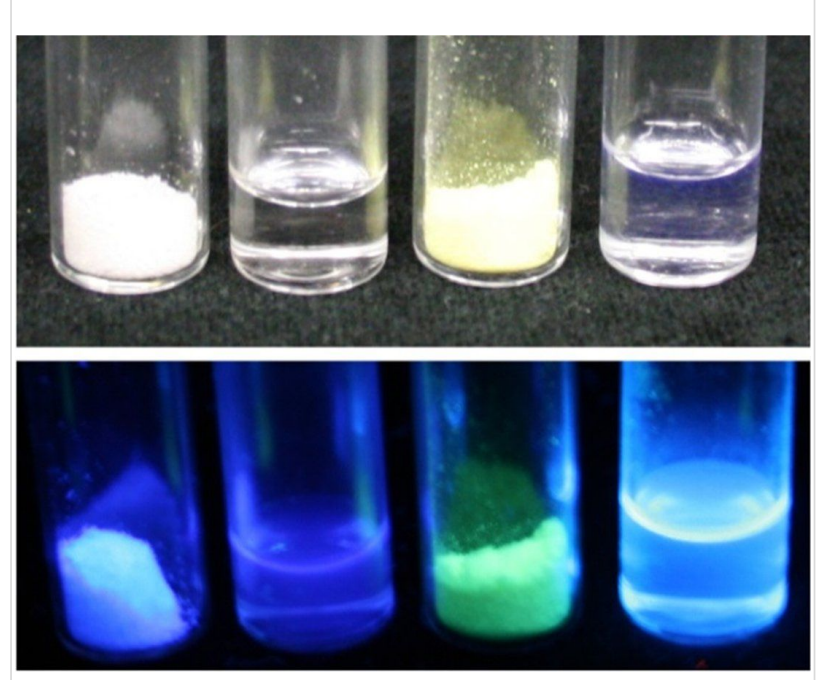

Figure 1: Compounds 2d (solid and THF solution) and $\mathbf{2 n}$ (solid and THF solution) (from left to right) under daylight (top) and under UV light (bottom, $\lambda_{\max , \mathrm{exc}}=366 \mathrm{~nm}$ ).

The most furans display intense, broad absorption bands between 321 and $358 \mathrm{~nm}$ with molar extinction coefficients between 21000 to $35000 \mathrm{~L} / \mathrm{mol} \mathrm{cm}^{-1}$. In addition redshifted shoulders appear between 336 and $377 \mathrm{~nm}$. Likewise the emission maxima are found between 367 and $439 \mathrm{~nm}$ and blueshifted shoulders appear between 351 and $424 \mathrm{~nm}$. The Stokes shifts $\tilde{v}$ determined from the absorption and emission

Table 2: Selected absorption and emission data (recorded in dichloromethane at $T=293 \mathrm{~K}$ ).

\begin{tabular}{|c|c|c|c|c|}
\hline Compound & $\begin{array}{c}\lambda_{\max , \text { abs }}[\mathrm{nm}]^{\mathrm{a}} \\
\left(\left[\mathrm{L} \cdot \mathrm{mol} \cdot \mathrm{cm}^{-1}\right]\right)\end{array}$ & $\lambda_{\max , \mathrm{em}}[\mathrm{nm}]$ & $\Delta \tilde{v}\left[\mathrm{~cm}^{-1}\right]^{\mathrm{b}}$ & $\Phi_{\mathrm{f}}$ \\
\hline $2 a$ & 327 (35000), $342 \mathrm{sh}$ & $358 \mathrm{sh}, 373$ & 3800 & $83 \% c$ \\
\hline $2 b$ & 314 (23000), $342 \mathrm{sh}$ & 359 sh, 375 & 5200 & $59 \%{ }^{c}$ \\
\hline 2c & 329 (33000), 344 sh & $360 \mathrm{sh}, 376$ & 3800 & $72 \%{ }^{c}$ \\
\hline $2 d$ & 331 (33000), $348 \mathrm{sh}$ & 360 sh, 379 & 3800 & $64 \%{ }^{c}$ \\
\hline $2 e$ & 331 (28000), $347 \mathrm{sh}$ & 362 sh, 379 & 3800 & $55 \%{ }^{c}$ \\
\hline $2 f$ & 331 (29000), $347 \mathrm{sh}$ & 362 sh, 381 & 4000 & $95 \%{ }^{c}$ \\
\hline $2 g$ & 340 (33000), $356 \mathrm{sh}$ & 378 sh, 391 & 3800 & $80 \%{ }^{c}$ \\
\hline $2 \mathrm{~h}$ & 347 (33000), $364 \mathrm{sh}$ & 377 sh, 395 & 3500 & $47 \% c$ \\
\hline $2 \mathbf{i}$ & $347(29000)$ & 424 sh, 436 & 5900 & $75 \%{ }^{d}$ \\
\hline $2 \mathbf{j}$ & 358 (26000), $377 \mathrm{sh}$ & 393 sh, 411 & 3600 & $100 \% d$ \\
\hline $2 k$ & 329 (32000), $345 \mathrm{sh}$ & 362 sh, 377 & 3900 & $80 \%{ }^{c}$ \\
\hline 21 & 353 (24000), $371 \mathrm{sh}$ & 389 sh, 407 & 3800 & $42 \%$ c,e \\
\hline $2 m$ & 321 (23000), $336 \mathrm{sh}$ & 351 sh, 367 & 3900 & $29 \%{ }^{c}$ \\
\hline $2 n$ & $343(23000)$ & 439 & 6400 & $69 \% d$ \\
\hline 20 & 323 (21000), $338 \mathrm{sh}$ & 353 sh, 368 & 3800 & $76 \%{ }^{\mathrm{c}}$ \\
\hline
\end{tabular}

${ }^{a} \mathrm{sh}=$ shoulder. ${ }^{b}$ The boldfaced absorption and emission maxima were used to calculate the Stokes shifts. ${ }^{c} p$-Terphenyl $\left(\Phi_{\mathrm{f}}=93 \%\right.$ in cyclohexane $)$ as a reference [40]. ${ }^{d}$ Coumarin $1\left(\Phi_{f}=73 \%\right.$ in EtOH $)$ as a reference [41]. ${ }^{\text {e }}$ ef. [26]: $\Phi_{f}=33 \%$ in acetonitrile. 
maxima range from 3500 to $6400 \mathrm{~cm}^{-1}$ and the quantum yields are quite large in a range from $\Phi_{\mathrm{f}}=29$ to $100 \%$. The compounds $2 \mathbf{b}, \mathbf{2 i}$ and $\mathbf{2 n}$ display unstructured broad absorption and emission bands and possess the largest Stokes shifts.

This peculiar effect could arise from considerable geometrical differences between the electronic ground state and the vibrationally relaxed excited state caused by significant distortion of the aryl substituents from coplanarity in the ground state [42]. Therefore, the geometries of the ground state structures of the compounds $\mathbf{2 a}, \mathbf{2} \mathbf{b}, \mathbf{2} \mathbf{i}, \mathbf{2} \mathbf{j}$, and $\mathbf{2 n}$ were optimized on the DFT level of theory (B3LYP functional [43-46] and the Pople 6-311G(d,p) basis set [47]) as implemented in Gaussian09 [48]. The computations applied the Polarizable Continuum Model (PCM) using dichloromethane as solvent [49]. All minima were confirmed by analytical frequency analyses. In conclusion, the computations clearly reveal that the ortho-aryl substituted compounds $\mathbf{2 b}, \mathbf{2 h}, \mathbf{2 i}$ and $\mathbf{2 n}$ are twisted from coplanarity while the other compounds are coplanar (Figure 2).

In the UV-vis spectra the similar planar structures $\mathbf{2 a}$ and $\mathbf{2 c}$ are bathochromically shifted in comparison to the twisted structure $\mathbf{2 b}$. The twisting from coplanarity also results in a lower fluorescence quantum yield $\Phi_{\mathrm{f}}$. The same holds true for the comparison of the constitutional isomers $\mathbf{2} \mathbf{i}$ and $\mathbf{2 j}$. Therefore, the twisted structure of $\mathbf{2} \mathbf{j}$ causes a larger Stokes shift and a much lower fluorescence quantum yield $\Phi_{\mathrm{f}}$. The huge Stokes shift originates from a considerable planarization in the excited state [42]. The absorption maximum of $\mathbf{2} \mathbf{h}$ is considerably shifted bathochromically in comparison to those of $\mathbf{2 c}, \mathbf{2 e}$, and $\mathbf{2 f}$. The DFT calculation on structure $\mathbf{2 h}$ reveals a twisted ground state structure. In the whole series compound $\mathbf{2} \mathbf{j}$ shows the most redshifted absorption maximum and the highest fluorescence quantum yield $\Phi_{\mathrm{f}}$. This finding correlates well with the planar ground state structure and an associated low Stokes shift. All studied representatives are potentially interesting singlet bluelight emitters.

In addition, the electronic properties of the furans $\mathbf{2}$ have been studied by cyclic voltammetry (Table 3 ). Most cyclovoltammograms display reversible Nernstian one-electron oxidations in the anodic region between 1.06 and $1.25 \mathrm{~V}$ (vs Ag/AgCl) (Table 3). Expectedly, with increasing electron density the oxidative potential diminishes. The compounds $\mathbf{2 f}, \mathbf{2 g}, \mathbf{2 l}$, and $\mathbf{2 n}$ could not be measured by cyclic voltammetry due to precipitation on the electrode. The determined oxidation potentials $E_{1 / 2}{ }^{0 /+1}$ vs $\mathrm{Ag} / \mathrm{AgCl}$ were recalculated vs the normal hydrogen electrode (NHE) and then transformed into $\mathrm{eV}$ [50]. The reduction potentials were calculated by subtraction of the $S_{1}-S_{0}$ energy gap (in eV) from the first oxidation potential $E_{1 / 2} 0 /+1$. This gap was estimated by the cross-section of the absorption and emission spectra. For the missing oxidation potentials of $\mathbf{2 f}$, $\mathbf{2 g}, \mathbf{2 m}$, and $\mathbf{2 l}$ the HOMO and LUMO energies were determined by DFT calculations [48]. For validation of the experimental and computational data the oxidation and reduction potentials were converted into the corresponding experimental HOMO and LUMO energies (for details see Supporting Information File 1). The plot of measured and calculated HOMO energies gives a reasonable linear correlation $\left(r^{2}=0.815\right.$, omitting the twisted compounds $\mathbf{2} \mathbf{b}, \mathbf{2 h}, \mathbf{2 i}$ and $\mathbf{2 n}$ ) with a mean deviation of $0.05 \mathrm{eV}$ (see Supporting Information File 1). Roughly a similar trend can be found for the HOMO-LUMO gap.

The inspection of the coefficient densities in the Kohn-Sham frontier molecular orbitals of the compounds $\mathbf{2} \mathbf{i}, \mathbf{2} \mathbf{j}$, and $\mathbf{2 n}$ underlines that the HOMO and the LUMO are delocalized over the whole molecule (Figure 3), which plausibly rationalizes the high extinction coefficient of the longest wavelength absorptions bands.

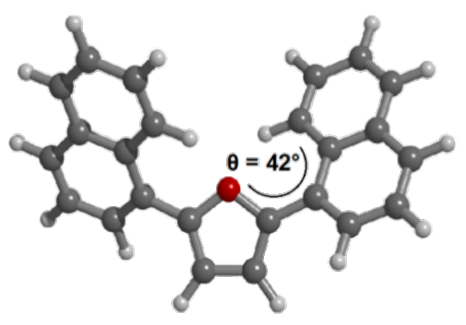

2i

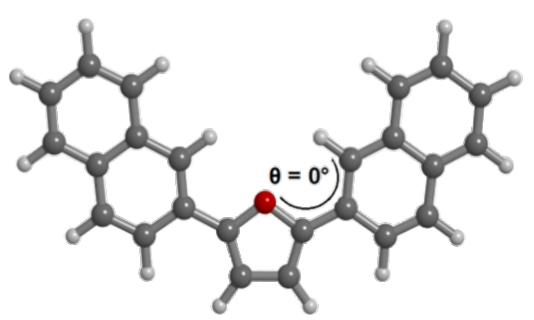

$2 \mathrm{j}$

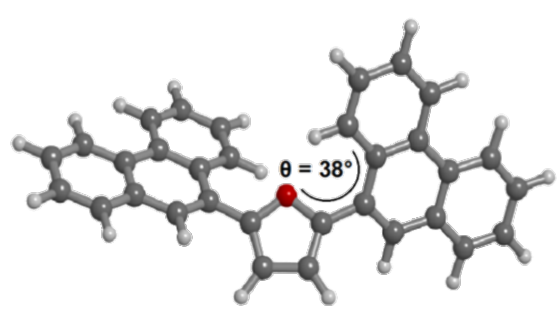

2n

Figure 2: Selected computed minimum conformations of the 2,5-diarylfurans $\mathbf{2} \mathbf{i}, \mathbf{2} \mathbf{j}$, and $\mathbf{2 n}$. 
Table 3: Selected cyclovoltammetric ${ }^{a}$ (recorded in dichloromethane at $293 \mathrm{~K}$ ) and computational ${ }^{\mathrm{b}}$ data.

\begin{tabular}{|c|c|c|c|c|c|c|c|c|c|}
\hline \multirow[t]{2}{*}{ Compound } & \multirow[t]{2}{*}{$E_{0}^{0 /+1}[\mathrm{~V}]^{\mathrm{c}}$} & \multirow[t]{2}{*}{$E_{1 / 2}^{0 /+1}[\mathrm{~V}]$ vs $\mathrm{NHE}^{\mathrm{c}}$} & \multirow[t]{2}{*}{$E_{1 / 2}{ }^{0 /-1}[\mathrm{~V}]$ vs $\mathrm{NHE}^{\mathrm{d}}$} & \multicolumn{2}{|c|}{$\mathrm{HOMO}[\mathrm{eV}]$} & \multicolumn{2}{|c|}{ LUMO [eV] } & \multicolumn{2}{|c|}{$\Delta E_{\text {HOMO-LUMO }}$} \\
\hline & & & & exp.e & calcd. ${ }^{d}$ & $\exp ^{f}$ & calcd. $^{\mathrm{b}}$ & exp. & calcd. \\
\hline $2 a$ & 1.25 & 1.45 & -2.11 & -5.60 & -5.57 & -2.04 & -1.60 & 3.56 & 3.97 \\
\hline $2 b$ & 1.19 & 1.39 & -2.18 & -5.54 & -5.59 & -1.97 & -1.51 & 3.57 & 4.08 \\
\hline 2c & 1.19 & 1.39 & -2.15 & -5.54 & -5.50 & -2.00 & -1.57 & 3.54 & 3.93 \\
\hline $2 d$ & 1.09 & 1.29 & -2.22 & -5.44 & -5.41 & -1.93 & -1.49 & 3.51 & 3.92 \\
\hline $2 e$ & 1.06 & 1.26 & -2.24 & -5.41 & -5.46 & -1.91 & -1.51 & 3.50 & 3.95 \\
\hline $2 f$ & - & - & - & - & -5.55 & - & -1.57 & - & 3.98 \\
\hline $2 g$ & - & - & - & - & -5.44 & - & -1.58 & - & 3.86 \\
\hline $2 \mathrm{~h}$ & 1.24 & 1.44 & -2.22 & -5.59 & -5.41 & -1.93 & -1.16 & 3.66 & 4.25 \\
\hline $2 \mathbf{i}$ & 1.15 & 1.35 & -1.81 & -5.50 & -5.54 & -2.34 & -1.81 & 3.16 & 3.73 \\
\hline $2 j$ & 1.10 & 1.30 & -1.94 & -5.45 & -5.46 & -2.21 & -1.93 & 3.24 & 3.53 \\
\hline $2 k$ & 1.16 & 1.36 & -2.17 & -5.51 & -5.53 & -1.98 & -1.56 & 3.53 & 3.97 \\
\hline 21 & - & - & - & - & -5.37 & - & -1.70 & - & 3.67 \\
\hline $2 m$ & - & - & - & - & -5.44 & - & -1.38 & - & 4.06 \\
\hline $2 n$ & 1.14 & 1.34 & -1.82 & -5.49 & -5.59 & -2.33 & -1.81 & 3.16 & 3.78 \\
\hline 20 & 1.24 & 1.44 & -2.17 & -5.59 & -5.57 & -1.98 & -1.60 & 3.61 & 3.97 \\
\hline
\end{tabular}

a $0.1 \mathrm{M}$ electrolyte: $\left[\mathrm{Bu}_{4} \mathrm{~N}\right]\left[\mathrm{PF}_{6}\right](120 \mathrm{mg}$ in $3 \mathrm{~mL}$ dichloromethane), Pt working electrode, $\mathrm{Pt}$ counter electrode, $\mathrm{Ag} / \mathrm{AgCl}$ (in $\mathrm{KCl})$ reference electrode. ${ }^{\mathrm{b}}$ Calculated with Gaussian09, B3LYP/6-311G(d,p). ${ }^{\mathrm{c}} E_{1 / 2}=E_{0}+N H E$ (with NHE $\left.\left(3 \mathrm{M} \mathrm{KCl} \mathrm{Ag/Ag}{ }^{+}\right)=0.198 \mathrm{~V}\right)$.

${ }^{\mathrm{d}} E_{0-1 / 20 /-10}=E_{1 / 2}-\frac{h v}{\lambda_{\text {cross }}}$ (with cross-section of absorption and emission spectra).
${ }^{\mathrm{e}} E_{H O M O}=-\left(\begin{array}{c}E_{1}(O x 1)-E_{\frac{F C}{2}} \\ \frac{F c+}{2}\end{array}\right)-4.6 \mathrm{eV} 8 \cdot{ }^{\mathrm{f}} E_{L U M O}=-\left(\begin{array}{c}E_{0-0}-E_{\frac{F c}{F c+}}\end{array}\right)-4.6 \mathrm{eV}$.

LUMO:
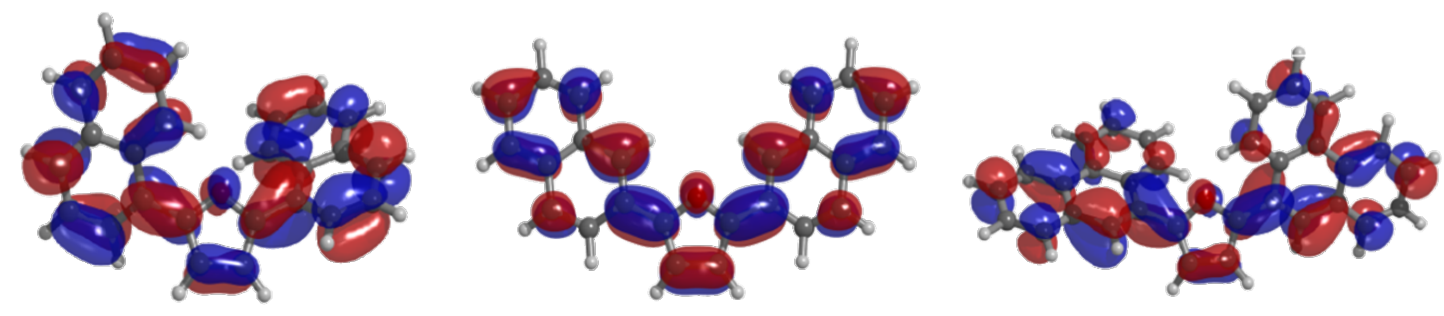

HOMO:

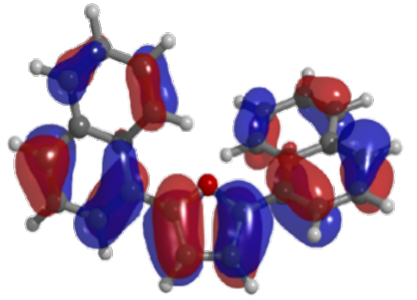

2i

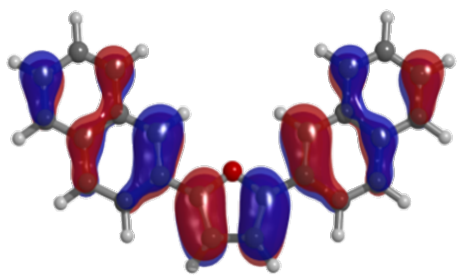

2j

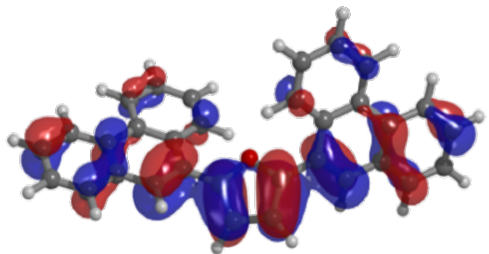

2n

Figure 3: Kohn-Sham HOMOs (bottom) and LUMOs (top) of the compounds $\mathbf{2} \mathbf{i}, \mathbf{2} \mathbf{j}$, and $\mathbf{2 n}$ (calculated on the DFT level of theory (B3LYP/6$311 G(d, p))$. 


\section{Conclusion}

In summary we have disclosed a concise and efficient microwave-assisted pseudo five-component synthesis of symmetrical 2,5-di(hetero)arylfurans in a one-pot fashion, which opens a ready access to biologically active furan derivatives. In addition the investigation of the photophysical properties of these compounds reveals an intense blue luminescence in solution approaching unity for the fluorescence quantum yield $\Phi_{\mathrm{f}}$ of distinct derivatives. Computations account for significant distortions from coplanarity in the electronic ground state and the computed HOMO energies correlate with the first reversible oxidation potentials determined by cyclic voltammetry.

\section{Experimental}

Pseudo five-component synthesis of 2a [51] in a manner similar to [38]): A mixture of iodobenzene (3a, $408 \mathrm{mg}$, $2.00 \mathrm{mmol}), \mathrm{PdCl}_{2}\left(\mathrm{PPh}_{3}\right)_{2}(28.1 \mathrm{mg}, 0.04 \mathrm{mmol}, 2 \mathrm{~mol} \%$ ), and $\mathrm{CuCl}$ (7.92 mg, $0.08 \mathrm{mmol}, 4 \mathrm{~mol} \%$ ) was dissolved in DMSO $(2.00 \mathrm{~mL})$ in a $80 \mathrm{~mL}$ microwave vessel equipped with a stirring bar and a septum and was degassed with $\mathrm{N}_{2}$ for $5 \mathrm{~min}$. After addition of trimethylsilylacetylene $(0.42 \mathrm{~mL}, 3.00 \mathrm{mmol})$ and dry triethylamine $(0.55 \mathrm{~mL}, 4.00 \mathrm{mmol})$ the solution was stirred at room temperature for $1 \mathrm{~h}$. Then, KF (232 mg, $4.00 \mathrm{mmol}$ ) was added and the reaction mixture was vigorously stirred under air in the open reaction vessel at room temperature for $16 \mathrm{~h}$. After the addition of $\mathrm{H}_{2} \mathrm{O}(144 \mathrm{mg}, 8.00 \mathrm{mmol})$, potassium hydroxide (449 $\mathrm{mg}, 16 \mathrm{mmol})$, and DMSO $(14.0 \mathrm{~mL})$ the mixture was heated in the microwave cavity at $130{ }^{\circ} \mathrm{C}$ for $1 \mathrm{~h}$. After cooling to room temperature the mixture was extracted with methylene chloride $(300 \mathrm{~mL})$ and brine $(500 \mathrm{~mL})$. The organic phase was dried with anhydrous $\mathrm{Na}_{2} \mathrm{SO}_{4}$ and the solvents were removed under reduced pressure. The residue was absorbed on Celite ${ }^{\circledR}$ and purified by column chromatography on silica gel with $n$-hexane as an eluent to give $96.0 \mathrm{mg}(0.44 \mathrm{mmol}, 44 \%)$ of the desired product as colorless crystals. $R_{\mathrm{f}}:=0.31$ ( $n$-hexane). $\mathrm{Mp} 84{ }^{\circ} \mathrm{C}\left(66-68{ }^{\circ} \mathrm{C}[51]\right) .{ }^{1} \mathrm{H}$ NMR (DMSO- $\left.d_{6}, 600 \mathrm{MHz}\right) \delta 7.08(\mathrm{~s}, 2 \mathrm{H}), 7.31\left(\mathrm{t},{ }^{3} J=7.4\right.$ $\mathrm{Hz}, 2 \mathrm{H}), 7.46\left(\mathrm{t},{ }^{3} J=7.8 \mathrm{~Hz}, 4 \mathrm{H}\right), 7.82\left(\mathrm{~d},{ }^{3} J=7.3 \mathrm{~Hz}, 4 \mathrm{H}\right)$; ${ }^{13} \mathrm{C}$ NMR (DMSO, $\left.150 \mathrm{MHz}\right) \delta 108.2(\mathrm{CH}), 123.4(\mathrm{CH}), 127.5$ $(\mathrm{CH}), 128.9(\mathrm{CH}), 130.0\left(\mathrm{C}_{\text {quat }}\right), 152.6\left(\mathrm{C}_{\text {quat }}\right) . \mathrm{GC}-\mathrm{MS}(\mathrm{m} / \mathrm{z}$ (\%)): $220\left(\mathrm{M}^{+}, 100\right), 191(13), 115\left(\left(\mathrm{M}-\mathrm{C}_{7} \mathrm{H}_{5} \mathrm{O}\right)^{+}, 41\right), 105$ $\left(\left(\mathrm{C}_{7} \mathrm{H}_{5} \mathrm{O}\right)^{+}, 22\right), 89(14), 77\left(\left(\mathrm{C}_{6} \mathrm{H}_{5}\right)^{+}, 51\right), 63$ (13), 51 (22); IR $(\mathrm{KBr}): \tilde{\mathrm{v}}=1479(\mathrm{w}) \mathrm{cm}^{-1}, 1446(\mathrm{w}), 1155(\mathrm{w}), 1022(\mathrm{~m}), 925$ $(\mathrm{w}), 910(\mathrm{w}), 794(\mathrm{~m}), 756(\mathrm{~s}), 689(\mathrm{~s}), 671(\mathrm{~m})$. Anal. calcd for $\mathrm{C}_{16} \mathrm{H}_{12} \mathrm{O}$ (220.3): C 87.25, H 5.49; Found: C 87.09, H 5.42; UV-vis $\left(\mathrm{CH}_{2} \mathrm{Cl}_{2}\right): \lambda_{\max }(\varepsilon): 327 \mathrm{~nm}\left(35000 \mathrm{~L} \cdot \mathrm{mol}^{-1} \cdot \mathrm{cm}^{-1}\right), 342$ (22000). Fluorescence $\left(\mathrm{CH}_{2} \mathrm{Cl}_{2}\right): \lambda_{\text {max }}: 358 \mathrm{~nm}$. Stokes shift $\Delta \widetilde{v}=3800 \mathrm{~cm}^{-1}$. Quantum yield: $\Phi_{\mathrm{f}}=83 \%$ (Ref.: $p$-terphenyl $\left(\Phi_{\mathrm{f}}=93 \%\right.$ in cyclohexane) $)$. Cyclic voltammetry $\left(\mathrm{CH}_{2} \mathrm{Cl}_{2}\right)$ : $E_{1 / 2}{ }^{0 /+1}=1.25 \mathrm{~V}$.

\section{Supporting Information}

For experimental details of the optimization studies of the cyclization step (compound 2a), of general procedure of the Sonogashira-Glaser cyclization synthesis of the 2,5-di(hetero)arylfurans 2, for UV-vis, fluorescence, and NMR spectra and cyclovoltammograms of the compounds 2, and for computational data of the DFT calculations on the structures 2 of see Supporting Information.

\section{Supporting Information File 1}

Experimental procedures, spectroscopic and analytical data of all compounds 2 .

[http://www.beilstein-journals.org/bjoc/content/ supplementary/1860-5397-10-60-S1.pdf]

\section{Acknowledgements}

The support of this work by the Fonds der Chemischen Industrie is gratefully acknowledged.

\section{References}

1. Müller, T. J. J., Ed. Multicomponent Reactions; Science of Synthesis Series; Georg Thieme Verlag KG: Stuttgart, 2014.

2. Sunderhaus, J. D.; Martin, S. F. Chem.-Eur. J. 2009, 15, 1300-1308. doi:10.1002/chem.200802140

3. Isambert, N.; Lavilla, R. Chem.-Eur. J. 2008, 14, 8444-8454. doi: $10.1002 /$ chem. 200800473

4. Orru, R. V. A.; de Greef, M. Synthesis 2003, 1471-1499. doi:10.1055/s-2003-40507

5. Bonne, D.; Coquerel, Y.; Constantieux, T.; Rodriguez, J. Tetrahedron: Asymmetry 2010, 21, 1085-1109. doi:10.1016/j.tetasy.2010.04.045

6. Müller, T. J. J.; D’Souza, D. M. Pure Appl. Chem. 2008, 80, 609-620. doi:10.1351/pac200880030609

7. Burke, M. D.; Schreiber, S. L. Angew. Chem., Int. Ed. 2004, 43, 46-58. doi:10.1002/anie.200300626

8. Dömling, A. Chem. Rev. 2006, 106, 17-89. doi:10.1021/cr0505728

9. Weber, L. Curr. Med. Chem. 2002, 9, 2085-2093. doi:10.2174/0929867023368719

10. Shaw, A. Y.; Denning, C. R.; Hulme, C. Synthesis 2013, 45, 459-462. doi:10.1055/s-0032-1317983

11. Müller, T. J. J. In Functional Organic Materials. Syntheses, Strategies, and Applications; Müller, T. J. J.; Bunz, U. H. F., Eds.; Wiley-VCH Verlag GmbH \& Co. KGaA: Weinheim, 2007; pp 179-223.

12. Karpov, A. S.; Merkul, E.; Oeser, T.; Müller, T. J. J. Chem. Commun. 2005, 2581-2583. doi:10.1039/B502324F

13. Willy, B.; Müller, T. J. J. ARKIVOC 2008, i, 195-208.

14. Keayand, B. A.; Dibble, P. W. In Comprehensive Heterocyclic Chemistry II, 2nd ed.; Katritzky, A. R.; Reesand, C. W.; Scriven, E. F. V., Eds.; Elsevier: Oxford, 1997; pp 395-436.

15. Das, B. P.; Boykin, D. W. J. Med. Chem. 1977, 20, 531-536. doi:10.1021/jm00214a014

16. Majumder, P.; Saha, S. Phytochemistry 1978, 17, 1439-1440. doi:10.1016/S0031-9422(00)94610-7 
17. Masood, M.; Tiwari, K. P. Phytochemistry 1981, 20, 295-296. doi:10.1016/0031-9422(81)85110-2

18. Thuita, J. K.; Karanja, S. M.; Wenzler, T.; Mdachi, R. E.; Ngotho, J. M.; Kagira, J. M.; Tidwell, R.; Brun, R. Acta Trop. 2008, 108, 6-10. doi:10.1016/j.actatropica.2008.07.006

19. Wenzler, T.; Boykin, D. W.; Ismail, M. A.; Hall, J. E.; Tidwell, R. R.; Brun, R. Antimicrob. Agents Chemother. 2009, 53, 4185-4192. doi:10.1128/AAC.00225-09

20. Barrett, M. P.; Croft, S. L. Br. Med. Bull. 2012, 104, 175-196. doi:10.1093/bmb/lds031

21. Nieves-Neira, W.; Rivera, M. I.; Kohlhagen, G.; Hursey, M.; Pourquier, P.; Sausville, E. A.; Pommier, Y. Mol. Pharmacol. 1999, 56, 478-484.

22. Chène, P. Nat. Rev. Cancer 2003, 3, 102-109. doi:10.1038/nrc991

23. Issaeva, N.; Bozko, P.; Enge, M.; Protopopova, M.; Verhoef, L. G. G. C.; Masucci, M.; Pramanik, A.; Selivanova, G. Nat. Med. 2004, 10, 1321-1328. doi:10.1038/nm1146

24. Liu, C.-Y.; Luh, T. Org. Lett. 2002, 4, 4305-4307. doi:10.1021/ol026941t

25. Altınok, E.; Friedle, S.; Thomas, S. W., III. Macromolecules 2013, 46, 756-762. doi:10.1021/ma3025656

26. Seixas de Melo, J.; Elisei, F.; Becker, R. S. J. Chem. Phys. 2002, 117, 4428-4435. doi:10.1063/1.1498115

27. Kutsyna, L. M.; Sidorova, R. P.; Voevoda, L. V.; Ishchenko, I.; Demchenko, N. P. Bull. Acad. Sci. USSR, Phys. Ser. (Engl. Transl.) 1962, 26, 1304-1322.

28. Amarnath, V.; Amarnath, K. J. Org. Chem. 1995, 60, 301-307. doi:10.1021/jo00107a006

29. Rao, M. L. N.; Awasthi, D. K.; Talode, J. B. Synlett 2012, 23 , 1907-1912. doi:10.1055/s-0032-1316567

30. Nun, P.; Dupuy, S.; Gaillard, S.; Poater, A.; Cavallo, L.; Nolan, S. P. Catal. Sci. Technol. 2011, 1, 58-61. doi:10.1039/C0CY00055H

31. Kramer, S.; Madsen, J. L. H.; Rottländer, M.; Skrydstrup, T. Org. Lett. 2010, 12, 2758-2761. doi:10.1021/ol1008685

32. Jiang, H.; Zeng, W.; Li, Y.; Wu, W.; Huang, L.; Fu, W. J. Org. Chem. 2012, 77, 5179-5183. doi:10.1021/jo300692d

33. Fillmore, F.; Hengyao, L.; Qingbei, Z. J. Org. Chem. 1994, 59, 4350-4354. doi:10.1021/jo00094a062

34. Pérez, M.; Cano, R.; Yus, M.; Ramón, D. J. Synthesis 2013, 45 , 1373-1379. doi:10.1055/s-0032-1316872

35. Müller, T. J. J. Top. Organomet. Chem. 2006, 19, 149-205. doi:10.1007/3418_012

36. Merkul, E.; Klukas, F.; Dorsch, D.; Grädler, U.; Greiner, H. E.; Müller, T. J. J. Org. Biomol. Chem. 2011, 9, 5129-5136. doi:10.1039/C1OB05586K

37. Merkul, E.; Urselmann, D.; Müller, T. J. J. Eur. J. Org. Chem. 2011, 238-242. doi:10.1002/ejoc.201001472

38. Urselmann, D.; Antovic, D.; Müller, T. J. J. Beilstein J. Org. Chem. 2011, 7, 1499-1503. doi:10.3762/bjoc.7.174

39. De Oliveira, R. B.; De Souza-Fagundes, E. M.; Siqueira, H. A. J.; Leite, R. S.; Domici, C. L.; Zani, C. L. Eur. J. Med. Chem. 2006, 41, 756-760. doi:10.1016/j.ejmech.2006.03.010

40. Pavlopoulos, T. G.; Hammond, P. R. J. Am. Chem. Soc. 1974, 96, 6568-6579. doi:10.1021/ja00828a005

41. Jones, G., II; Jackson, W. R.; Choi, C.; Bergmark, W. R. J. Phys. Chem. 1985, 89, 294-300. doi:10.1021/j100248a024

42. Lakowicz, J. R. Principles of Fluorescence Spectroscopy, 3rd ed.; Springer: Berlin/Heidelberg, 2006; chapter 1.9.

43. Lee, C.; Yang, W.; Parr, R. G. Phys. Rev. B 1988, 37, 785-789. doi:10.1103/PhysRevB.37.785
44. Becke, A. D. J. Chem. Phys. 1993, 98, 5648-5652. doi:10.1063/1.464913

45. Kim, K.; Jordan, K. D. J. Phys. Chem. 1994, 98, 10089-10094. doi:10.1021/j100091a024

46. Stephens, P. J.; Devlin, F. J.; Chabalowski, C. F.; Frisch, M. J. J. Phys. Chem. 1994, 98, 11623-11627. doi:10.1021/j100096a001

47. Krishnan, R.; Binkley, J. S.; Seeger, R.; Pople, J. A. J. Chem. Phys. 1980, 72, 650-654. doi:10.1063/1.438955

48. Gaussian 09, Revision A.02; Gaussian, Inc.: Wallingford CT, 2009.

49. Scalmani, G.; Frisch, M. J. J. Chem. Phys. 2010, 132, 114110-114124. doi:10.1063/1.3359469

50. Pommerehne, J.; Vestweber, H.; Guss, W.; Mahrt, R. F.; Bässler, H.; Porsch, M.; Daub, J. Adv. Mater. 1995, 7. doi:10.1002/adma.19950070608

51. Zhang, M.; Jiang, H.-F.; Neumann, H.; Beller, M.; Dixneuf, P. H. Angew. Chem., Int. Ed. 2009, 48, 1681-1684.

doi:10.1002/anie.200805531

\section{License and Terms}

This is an Open Access article under the terms of the Creative Commons Attribution License

(http://creativecommons.org/licenses/by/2.0), which permits unrestricted use, distribution, and reproduction in any medium, provided the original work is properly cited.

The license is subject to the Beilstein Journal of Organic Chemistry terms and conditions:

(http://www.beilstein-journals.org/bjoc)

The definitive version of this article is the electronic one which can be found at: doi:10.3762/bjoc. 10.60 